Wright State University

CORE Scholar

Physics Faculty Publications

Physics

1979

\title{
Electrical Resistivity Studies of Order-Disorder Phenomena in V2H and V2D
}

Gust Bambakidis

Wright State University - Main Campus, gust.bambakidis@wright.edu

M. W. Pershing

R. C. Bowman

Follow this and additional works at: https://corescholar.libraries.wright.edu/physics

Part of the Physics Commons

\section{Repository Citation}

Bambakidis, G., Pershing, M. W., \& Bowman, R. C. (1979). Electrical Resistivity Studies of Order-Disorder Phenomena in V2H and V2D. Bulletin of the American Physical Society, 24 (3), 464-464.

https://corescholar.libraries.wright.edu/physics/244

This Conference Proceeding is brought to you for free and open access by the Physics at CORE Scholar. It has been accepted for inclusion in Physics Faculty Publications by an authorized administrator of CORE Scholar. For more information, please contact library-corescholar@wright.edu. 
(TSH) in these bcc alloys. The TSH's, which are marked by the onset of hydride precipitation from the saturated solid solution, were determined resistometrically from discontinuities in $d p / d T$. Increases in the apparent TSH in $\mathrm{Nb}-\mathrm{TI}$ alloys are belleved to be due to the presence of energetically favorable interstitial sites, or "traps", in the vicinlty of the substitutional $\mathrm{T} 1$ solute atoms. The magnitude of the TSH enhancements suggests that TI is a more effective trapping center than $\mathrm{Ta}$, but less effective than V. Proposed explanations for this behavior based upon electronic and atom-size considerations will be discussed.

*Work supported by the U.S. Department of Energy.

KJ 6 Electrical Resistivity Studies of Order-Disorder Phenomena in $\mathrm{V}_{2} \mathrm{H}$ and $\mathrm{V}_{2} \mathrm{D}$. G. BAMBAKIDIS and M.W.PERSHING* Wright State University, and R. C. BOWMAN, JR., Mound Facility**.--There is a marked isotope effect in the $\mathrm{V}-\mathrm{H}$ (D) phase diagrams. The disordering of the $H(D)$ on the octahedral sublattice in the $B$ phase is different for $\mathrm{V}-\mathrm{H}$ and $V-D$. From the non-linearity in the $\rho$ versus $T$ curves for $\mathrm{V}_{2} \mathrm{H}(\mathrm{D})$ we have obtained the temperature variation of the LRO parameter for $\mathrm{H}$ and $\mathrm{D}$. For $\mathrm{V}_{2} \mathrm{H}$ the results indicate a second-order transition within the $B$ phase before the onset of the $\alpha$ phase. The LRO parameter agrees closely with that inferred from powder neutron diffraction measurements 1 . For $\mathrm{V}_{2} \mathrm{O}$ a first-order $\beta \rightarrow \alpha$ transition is indicated. Our LRO parameter in this case differs significantly from the neutron diffraction results 2 but agrees well with that inferred from $X$-ray diffraction 3 . *Supported by USDOE through Mound Co-op Program. $\star \star$ Operated by Monsanto Research Corporation for USDOE under Contract No. EY-76-C-04-0053.

$1_{H}$. Asano et al, J. Phys. Soc. Jap. 41, 974 (1976).

2H. Asano et al, Paris Cong. H2 in Mets. (1977).

3H. Metzger et al, phys. stat. sol. 247, 631 (1978).

KJ 7 X-dependent Optical Studies of $\mathrm{LaH}_{\mathrm{X}}$. D. J. PETERMAN, D. T. PETERSON, Ames Laboratory-USDOE* and

J. H. WEAVER, Synchrotron Radiation Center, University of Wisconsin-Madison.--Optical absorptivity experiments in the photon energy range of $0.2-4.5 \mathrm{eV}$ for various concentrations of hydrogen in $\mathrm{CaF}_{2}$-structured $\mathrm{LaH}_{\mathrm{x}}$ have been performed. The measured quantitles were used to determine the frequency-dependent dielectric functions. The results have been interpreted in 1ight of previous experImental and theoretical studies of the electronic structure of $\mathrm{ScH}_{2}$ and $\mathrm{YH}_{2} .1,2$ Based on the results of that earller work, one would expect hydrogen to occupy a substantial number of octahedral sites in $\mathrm{LaH}_{2}$ - perhaps giving rise to 'new' interband transitions. Such transitions have been observed and their concentration dependence allows us to classify the observed interband transitions as to whether or not they artse from octahedral site occupation.

*Work supported by USDOE

$1_{J}$. H. Weaver, R. Rose1, and D. T. Peterson, Phys. Rev. (to be published).

2D. J. Peterman, B. N. Harmon, J. Marchiando, and J. H Weaver, Phys. Rev. (to be published).

KJ 8 Sample Shape-Dependent Phase Transition of Hydrogen in Niobium, $H$. ZABEL, University of Houston*, H. PEISL, University of Munich. ${ }^{\star \star_{-}-\text {The } \alpha-\alpha}$ phase transition of hydrogen in Niobium closely resembles a gas-liquid transition of a real gas. The hydrogen atoms interact mainly via the long range elastic distortion field of the host metal atoms. The theory of elastic interaction and phase transition in coherent metalhydrogen systems ${ }^{1}$ predicts strongely depressed critical fluctuations at the critical point $\left(C_{c}=0.31 \mathrm{H} / \mathrm{Nb}\right.$, $T_{c}=171^{\circ} \mathrm{C}$ ). Only a few modes become unstable below $T_{C}$ on isochoral cooling of $\mathrm{Nb}$ samples, after in situ loading with hydrogen above $T_{f}$. It will be shown by means of $X$-ray scattering that those modes vary macroscopically over the whole sample size. The density modes depend sensitively on the sample geometry due to the fulfill. ment of the elastic boundary condition. Coherent hydrogen fluctuations are observed down to 40 degrees below $T_{C}$.

*Supported by U.S. DOE Contract EY-76-S-05-5111 **Supported by Bundesministerium fur Forschung and Technologie

${ }^{1} \mathrm{H}$. Wagner and H. Horner, Adv. Phy. 23, 587 (1974)

KJ 9 Phase Equilibria and Hydrogen Trapping in Dilute Alloys of Vanadium in Nloblum,* M. A. PICK and D. 0 . WELCH, Brookhaven Nat' 1 , Lab.--The effect of dilute vanadium additions to nlobium on hydrogen absorption was studied by measuring the tempersture dependent equilib. rium hydrogen partial pressure for pure $\mathrm{Nb}$, Nb+6at. $\mathrm{WV}$, and Nb+9at. \%v. A theoretical model of the effect of hydrogen trapping on phase equilibria in the $\alpha-a$ ' region of such systems was constructed. The results indicate that the $\mathrm{H}-\mathrm{V}$ binding energy 18 less than previously thought. ${ }^{1}$ A value of $.07 \mathrm{eV}$ is obtained from the depression of the $\alpha-\alpha^{\prime}$ critical temperature, but the shape of the pressure isothems suggests that this is an upper 1imit. The measured heat of solution decreases from -37.0 to -38.6 to $-38.8 \mathrm{kJg}-\mathrm{atom}^{-1}$ going from pure $\mathrm{Nb}$ to $\mathrm{Nb}+$ 6at. \% to $\mathrm{Nb}+9 \mathrm{at} . \% \mathrm{~N}$.

*Research supported by the DIv, of Basic Energy Sciences of DOE.

1Y. Sasaki and M. Amano, Proc. 2nd Int'1. Conf, on lydrogen in Meta1s, Vo1. 4, Pergamon Press (1977).

KJ 10 Heat Capacity and Disorder in $\mathrm{ScD}_{x}$. MARVIN MOSs, Sandia Labs. ${ }^{+}$- Excess heat capacity in $S_{C D}(x=0-1.83)$ In the range $298-1000 \mathrm{~K}$ is greatest for $x \approx 1$. This can be explained by a disorder model which has been appliod to cation-disordered phases in which a larger number of sites than mobile species leads to a configurational contribution to the entropy.1 It 1s assumed that highenergy interstitial sites are created by the introduction of deuterium, 2 the occupation of the sites being temperature dependent. A two-level model for site energies leads to maxima in the entropy and heat capacity for mid-range values of $x$.

* Work supported by the U.S. Department of Energy (DOB), under contract AT (29-1)-789.

A U.S. DOE factlity.

$1 \mathrm{H}$. Wiedersich and S. Geller in The Chenistry of Extended Defects in Non-Metallic Soljds, Eds. L. Eying and M. O'Keeffe (North-Holland Pub. Co., 1970), p. 629. 2 A. L. G. Rees, Trans. Faraday Soc. 50, 335 (1954).

\section{KJ 11 Evidence for Ordered Octahedral Protons Around} Dilute Er in YH.* E. L. VENTURIII, Sandia Labs.**-We present evidence for ordered arrangements of octahedral protons around dilute $\mathrm{Br}$ lons in $\mathrm{YH}_{\mathrm{X}}$ using electron spin resonance (ESR) of the Br in powdered hydride samples. When the hydrogen to metal ratio $x$ is less than 2, we observe an 1sotropic ESR signal plus two distinct uniaxdal resonances. The 1sotropic signal arises from an $\mathrm{Br}$ lon with eight nearest-neighbor tetrahedral protons (cubic site symetry), and the uniaxial resonances correspond to $\mathrm{Br}$ ions with either one or two additional next-nearest-neighbor octahedral protons. A sample of $\mathrm{YH}_{2,4}$ : Fr shows a new ESR signal from a site with biaxial symmetry (three unique axes) plus the isotropic signal fran Fr in a cubic site, but not the uniaxial site resonances fust discussed. We have tentatively identified the biaxial $\mathrm{Br}$ site as the mer- $\mathrm{XA}_{3}$ structure recently reported for stoichiometric $\operatorname{PrD}_{2.5^{\circ}}$ In this structure all elght tetrahedral proton sites are filled, and there are three ordered octahedral protons.

*Work sponsored by the U.S. Department of Energy under Contract AT(29-1)-789.

**A Department of Energy facillity.

KJ 12 Proton Distribution in Vicinity of a Rare Eartl Impurity in a Hydride.* P.M. RICHARDS, Sandia Labs.* Recent ESR and earlier Mössbauer studies of dilute Er 